\title{
EMERGENCE OF NDM-1 AMONG CARBAPENEM- RESISTANT KLEBSIELLA PNEUMONIAE IN IRAQI HOSPITALS
}

\author{
NADHEEMA HAMMOOD HUSSEIN* \\ Department of Biology, Branch of Biotechnology, College of Science, Al-Mustansiriyah \\ University, Baghdad, Iraq
}

(Received: 21 February 2017; accepted: 18 May 2017)

\begin{abstract}
Carbapenems are the last drugs of choice apart from colistin against serious infections caused by Gram-negative bacteria. However, there are increasing number of reports indicating prevailing emergence of metallo- $\beta$-lactamase (MBL)-producing clinical isolates worldwide and among them New Delhi MBL (NDM) is the most prevalent one. This study reports NDM-1 for the first time among Klebsiella pneumoniae from hospitalized patients in Baghdad, Iraq. Fifty-five clinical isolates of $K$. pneumoniae resistant to carbapenem were investigated from burned wounds, sputum, and blood samples. The susceptibility to different antibiotics was tested by VITEK-2 system. All strains were multidrug-resistant and they showed nine different antimicrobial-resistant patterns (A-I) and the most effective antibiotic on these strains was levofloxacin (85.45\%). The phenotypic detection of carbapenemases by MASTDISCS D70C revealed 29 (52.73\%) strains were MBL-producing, out of 55 were carbapenem-resistant $K$. pneumoniae strains. The $b l a_{\mathrm{NDM}-1}$ and other MBL genes were detected by conventional PCR and the result showed 37 (67.27\%) strains positive for $b l a_{\mathrm{NDM}-1}$ gene and only $5(9.1 \%)$ strains harbored $b l a_{\mathrm{IMP}}$ gene, while all strains were negative for $b l a_{\mathrm{VIM}}, b l a_{\mathrm{SIM}}, b l a_{\mathrm{GIM}}$, and $b l a_{\mathrm{SPM}}$ genes. Our results showed the coexistence of both $b l a_{\mathrm{NDM}-1}$ and $b l a_{\mathrm{IMP}}$ genes in three strains of $K$. pneumoniae, while indicated widespread NDM-1 in Baghdad, Iraq. Hence, it is necessary to follow proper infection control practices and physicians should be aware of the patients with such risk factors.
\end{abstract}

Keywords: K. pneumoniae, carbapenemases, carbapenem-resistance, $b l a_{\mathrm{NDM}-1}$ gene, MBL genes

\section{Introduction}

Klebsiella pneumoniae is a member of the family Enterobacteriaceae that causes severe infections [1], particularly respiratory tract infections, blood stream

*Corresponding author; E-mail: nadheema_a@yahoo.com 
infections, and urinary tract infections. During the past decades, it became an important cause of nosocomial infections [2]. K. pneumoniae is considered to be the second most common cause of nosocomial Gram-negative pathogen after Escherichia coli [3]. It has emerged as one of the most antibiotic-resistant pathogen responsible for outbreaks in the health-care systems [1]. The growing increase in the rates of antimicrobial resistance is a major cause for concern in Enterobacteriaceae family, particularly E. coli and K. pneumoniae [4]. Broadspectrum carbapenems are often considered as last therapeutic choices for treatment of infections due to multidrug-resistant Gram-negative bacteria $[5,6]$. The emergence of carbapenem-resistant Enterobacteriaceae is increasingly notified worldwide and is becoming an important topic in health-care systems [7]. In K. pneumoniae, resistance to carbapenems is mainly related to the production of carbapenem-hydrolyzing $\beta$-lactamase [8]. Enterobacteriaceae-producing New Delhi metallo- $\beta$-lactamase (NDM) presents a recognized threat to the health-care system. The NDM-1 gene can spread rapidly and has been found in various bacterial species in health-care systems and also in the environment [9]. The aim of this study was to determine the presence of $b l a_{\mathrm{NDM}-1}$ and other metallo- $\beta$ lactamase (MBL) genes including IMP, VIM, SIM, GIM, and SPM genes among carbapenem-resistant $K$. pneumoniae isolated from hospitalized patients in two hospitals in Baghdad, Iraq.

\section{Methods}

Bacterial strains and susceptibility testing

Fifty-five carbapenem-resistant $K$. pneumoniae clinical strains were isolated from burned wounds, sputum, and blood samples of hospitalized patients in hospitals in Baghdad Medical city (The Burn Specialist Hospital, The Martyr Ghazi Al-Hariri Hospital, and Baghdad Teaching Hospital). These strains were isolated through a period extended from March 2014 to November 2015. Identification of $K$. pneumoniae strains was performed by conventional and automated (VITEK-2 system, bioMérieux, France) methods using ID-GNB cards according to the manufacturer's instructions.

Antibiotic susceptibility testing was performed by VITEK-2 system (bioMérieux, France) for the following antibiotics: imipenem, ertapenem, nitrofurantoin, ampicillin, cefazolin, amoxicillin/clavulanic acid, ampicillin/sulbactam, ceftriaxone, ceftazidime, piperacillin/tazobactam, cefepime, ciprofloxacin, levofloxacin, gentamicin, tobramycin, and trimethoprim/sulfamethoxazole using AST cards according to the manufacturer's instructions. 
Carbapenemases were phenotypically investigated by MASTDISCS D70C carbapenemase detection disc set (Mast Group Ltd., UK). Each bacterial suspension was adjusted to a turbidity equivalent to $0.5 \mathrm{McFarland}$ standard and then used to inoculate Mueller-Hinton agar plates and the plates were incubated overnight.

In this method, the inhibition zone diameters of disc B (carbapenem + MBL inhibitor), disc C (carbapenem + KPC inhibitor), and disc D (carbapenem + AmpC inhibitor) are compared with inhibition zone diameter of disc A (carbapenem without inhibitor). The inhibition zone diameters around the discs were measured and the results were estimated according to manufacturer's instructions. E. coli ATCC 25922 was used as the carbapenem-susceptible strain and it was obtained from Teaching Laboratories/Medical city, Baghdad.

\section{Molecular detection of carbapenemases by PCR assay}

Genomic bacterial DNA was extracted from all 36 carbapenem-resistant K. pneumoniae strains using a commercial purification system Presto Mini gDNA Bacteria Kit (Geneaid, Thailand). Primers used in this study (Alpha DNA, Canada) were provided in lyophilized form then dissolved in sterile deionized distilled water (Table I).

A simplex PCR amplification was carried out for detection of $b l a_{\mathrm{NDM}-1}$ in all carbapenem-resistant $K$. pneumoniae strains on a thermal cycler instrument (Agilent Sure Cycler 8800, Santa Clara, CA, USA) using the primers NDM-1

Table I. The sequences of primers used in this study

\begin{tabular}{llcc}
\hline Primers & \multicolumn{1}{c}{ Sequence $\left(5^{\prime} \rightarrow 3^{\prime}\right)$} & Product size $(\mathrm{bp})$ & Reference \\
\hline NDM-1-F & GGTGCATGCCCGGTGAAATC & 661 & {$[10]$} \\
NDM-1-R & ATGCTGGCCTTGGGGAACG & & \\
Pre-NDM-1-F & CACCTCATGTTTGAATTCGCC & 983 & {$[11]$} \\
Pre-NDM-1-R & CTCTGTCACATCGAAATCGC & & \\
IMP-F & GGAATAGAGTGGCTTAAYTCTC & 188 & \\
IMP-R & CCAAACYACTASGTTATCT & & \\
VIM-F & GATGGTGTTTGGTCGCATA & 390 & \\
VIM-R & CGAATGCGCAGCACCAG & & \\
SIM-F & TACAAGGGATTCGGCATCG & 570 & \\
SIM-R & TAATGGCCTGTTCCCATGTG & & \\
GIM-F & TCGACACACCTTGGTCTGAA & 477 & \\
GIM-R & AACTTCCAACTTTGCCATGC & & \\
SPM-F & AAAATCTGGGTACGCAAACG & 271 & \\
SPM-R & ACATTATCCGCTGGAACAGG & & \\
\hline
\end{tabular}


(661 bp) for the amplification of internal gene and Pre-NDM-1 (983 bp) for the amplification of entire gene sequence. The following program was separately used for each primer (NDM-1 and Pre-NDM-1): initial denaturation at $95{ }^{\circ} \mathrm{C}$ for $5 \mathrm{~min}$, followed by 35 cycles of denaturation at $95^{\circ} \mathrm{C}$ for $45 \mathrm{~s}$, annealing at $52^{\circ} \mathrm{C}$ for $45 \mathrm{~s}$, and extension at $72{ }^{\circ} \mathrm{C}$ for $60 \mathrm{~s}$, then final extension at $72{ }^{\circ} \mathrm{C}$ for $8 \mathrm{~min}$ [10]. The amplification reaction was separately prepared for each primer (NDM-1 and Pre-NDM-1) with a final volume $25 \mu$ of $12.52 \times$ Master mix (Promega, USA), $1 \mu \mathrm{l}$ of each primer (forward and reverse), $4 \mu \mathrm{l}$ of template DNA, and $6.5 \mu \mathrm{l}$ nuclease-free water. E. coli ATCC 25922 used as negative control.

Real-time PCR for detection of $\mathrm{bla}_{N D M-1}$ gene

Real-time PCR confirmed the detection of $b l a_{\mathrm{NDM}-1}$ gene. Real-time PCR was carried out for carbapenem-resistant K. pneumoniae strains by using Bio-Rad, USA. The amplification reaction was prepared in this study with a final volume $20 \mu \mathrm{l}$ of Go Taq qPCR Master mix (Promega, USA), $1 \mu \mathrm{l}$ of each forward and reverse primer (Pre-NDM-1 primer), $4 \mu$ l of template DNA, and $4 \mu$ l nuclease-free water. The same program of conventional PCR for detection of $b l a_{\mathrm{NDM}-1}$ gene was used. The standard curve was generated by performing three serial dilutions for the $b l a_{\mathrm{NDM}-1}$ gene.

\section{Multiplex PCR for other MBL genes}

Multiplex PCR amplification was carried out for the detection of $b l a_{\mathrm{IMP}}$, bla $_{\mathrm{VIM}}, b a_{\mathrm{SIM}}, b l a_{\mathrm{GIM}}$, and $b l a_{\mathrm{SPM}}$ genes in all carbapenem-resistant $K$. pneumoniae strains on a thermal cycler instrument (Agilent Sure Cycler 8800) using the following cycling conditions: $94{ }^{\circ} \mathrm{C}$ for $5 \mathrm{~min}$ as an initial denaturation step, followed by 36 cycles of $94{ }^{\circ} \mathrm{C}$ for $30 \mathrm{~s}, 52{ }^{\circ} \mathrm{C}$ for $40 \mathrm{~s}$, and $72{ }^{\circ} \mathrm{C}$ for $50 \mathrm{~s}$, final elongation step at $72{ }^{\circ} \mathrm{C}$ for $5 \mathrm{~min}$. The reaction of PCR consisted of $2 \times$ of 25 Master mix (Promega, USA), $1 \mu \mathrm{l}$ of each forward and reverse primers (bla $a_{\mathrm{IMP}}, b l a_{\mathrm{VIM}}, b l a_{\mathrm{SIM}}, b l a_{\mathrm{GIM}}$, and $\left.b l a_{\mathrm{SPM}}\right), 5 \mu \mathrm{l}$ of template DNA, and PCR grade water to a final volume $50 \mu \mathrm{l}$. E. coli ATCC 25922 was used as negative control [12]. The products of PCR were electrophoresed for $60 \mathrm{~min}$ and visualized with the aid of RedSafe staining (iNtRON, Korea) and UV transilluminator documentation system [13].

Sequencing of PCR products and phylogenetic analysis

Sequencing of bla $a_{\mathrm{NDM}-1}(983 \mathrm{bp}$ ) amplicons was carried out by Macrogen DNA Sequencing (Seoul, Korea), and the sequence of each amplicon was 
compared with the sequences in the GenBank nucleotide database/BLAST. The phylogenetic data were obtained by alignment and phylogenetic analysis of the sequences. Phylogenetic relationships were analyzed by MEGA6 program.

\section{Results}

\section{Bacterial strains}

During the period of March 2014 to November 2015, altogether 55 carbapenem-resistant $K$. pneumoniae strains were isolated, among them 23 $(41.82 \%)$ were isolated from blood specimens, 18 (32.73\%) were isolated from sputum specimens, and 14 (25.45\%) were isolated from burned wound specimens (Table II).

\section{Antibiotic susceptibility testing}

The antibiotic susceptibility test revealed that all 55 carbapenem-resistant $K$. pneumoniae clinical strains were multidrug-resistant and they were resistant to most antibiotics under test and it showed an elevated resistance to numerous classes of $\beta$-lactam and non- $\beta$-lactam antibiotics. On the other hand, these strains showed high sensitivity rate to levofloxacin $47(85.45 \%)$, followed by 36 $(65.45 \%)$ to trimethoprim/sulfamethoxazole and $33(60 \%)$ to ciprofloxacin as shown in Table III.

Also, the result showed nine different antimicrobial-resistant patterns among the 55 carbapenem-resistant $K$. pneumoniae strains under the study numbered from A to I, as summarized in Table IV (the strains that showing intermediate levels of susceptibility were considered as resistant).

\section{Phenotypic detection of carbapenemases}

The phenotypic detection of carbapenemases by MASTDISCS D70C was performed according to manufacturer's instructions in which the diameters of inhibition zones around the discs were measured and the bacterial strain recorded as MBL producer if disc $\mathrm{B}$ only showed a zone difference $\geq 5 \mathrm{~mm}$ than disc $\mathrm{A}$ (the discs $\mathrm{D}-\mathrm{A}$ and the discs $\mathrm{C}-\mathrm{A}$ should be $<4 \mathrm{~mm}$ ). The results of this test revealed among the 55 carbapenem-resistant $K$. pneumoniae strains, $29(52.73 \%)$ were identified as MBL-producing as shown in Table II and Figure 1. 


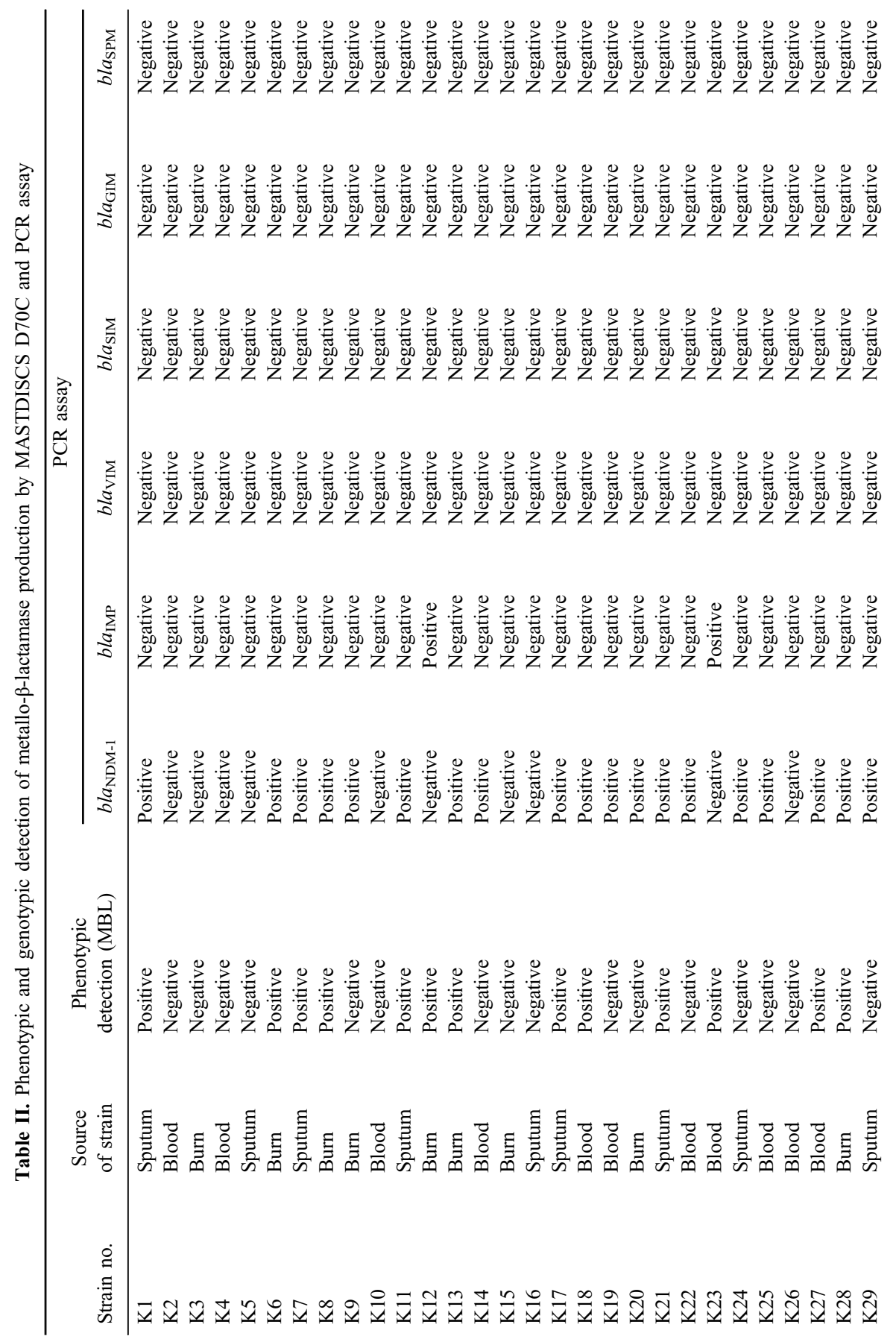




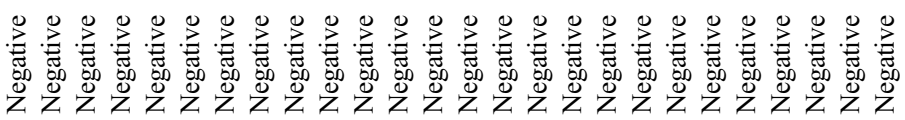

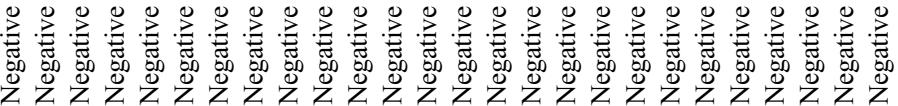

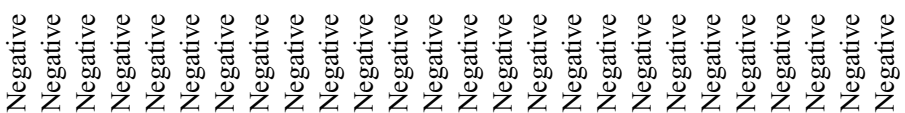

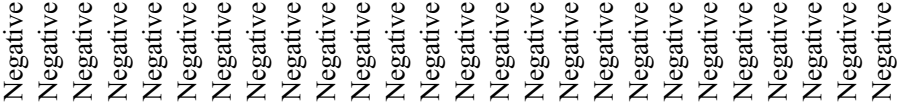

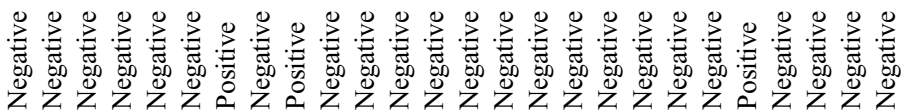

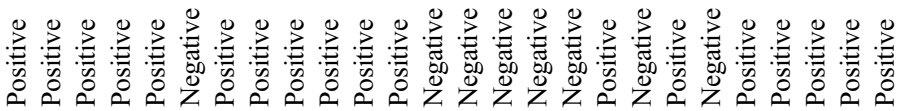

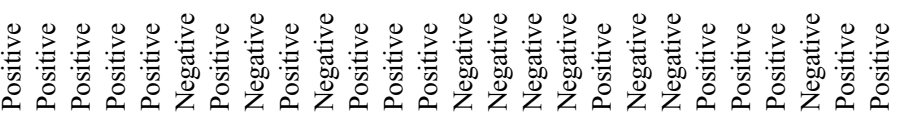

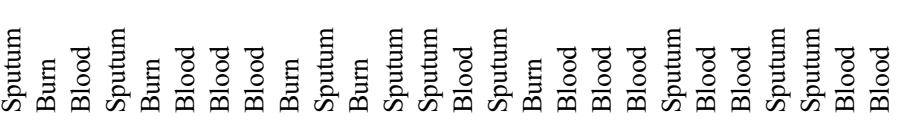

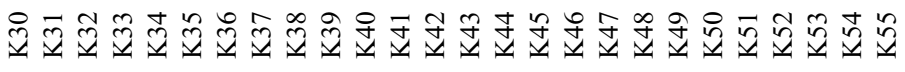


Table III. The results of antibiotic susceptibility test of $55 \mathrm{~K}$. pneumoniae clinical strains

\begin{tabular}{lccc}
\hline Antibiotics & $\mathrm{N}(\mathrm{S} \%)$ & $\mathrm{N}(\mathrm{I} \%)$ & $\mathrm{N}(\mathrm{R} \%)$ \\
\hline Ampicillin & $0(0)$ & $0(0)$ & $55(100)$ \\
Amoxicillin/clavulanic acid & $0(0)$ & $0(0)$ & $55(100)$ \\
Ampicillin/sulbactam & $0(0)$ & $0(0)$ & $55(100)$ \\
Piperacillin/tazobactam & $0(0)$ & $0(0)$ & $55(100)$ \\
Cefazolin & $0(0)$ & $0(0)$ & $55(100)$ \\
Ceftazidime & $0(0)$ & $0(0)$ & $55(100)$ \\
Ceftriaxone & $0(0)$ & $0(0)$ & $55(100)$ \\
Cefepime & $0(0)$ & $0(0)$ & $55(100)$ \\
Imipenem & $0(0)$ & $0(0)$ & $55(100)$ \\
Ertapenem & $0(0)$ & $0(0)$ & $55(100)$ \\
Gentamicin & $0(0)$ & $0(0)$ & $55(100)$ \\
Tobramycin & $1(1.82)$ & $0(0)$ & $54(98.18)$ \\
Ciprofloxacin & $33(60)$ & $16(29.1)$ & $6(10.9)$ \\
Levofloxacin & $47(85.45)$ & $1(1.82)$ & $7(12.73)$ \\
Nitrofurantoin & $8(14.55)$ & $17(30.91)$ & $30(54.54)$ \\
Trimethoprim/sulfamethoxazole & $36(65.45)$ & $0(0)$ & $19(34.55)$ \\
\hline
\end{tabular}

Note: N: number of strains; R: resistant; I: intermediate; S: sensitive.

Table IV. Antimicrobial-resistant patterns of $55 \mathrm{~K}$. pneumoniae clinical strains

\begin{tabular}{|c|c|c|c|}
\hline Pattern & Description & $\begin{array}{l}\text { Number } \\
\text { of strains }\end{array}$ & Percentage \\
\hline A & Resistant to all tested antibiotics & 4 & 7.27 \\
\hline $\mathrm{B}$ & Resistant to all tested antibiotics except levofloxacin & 10 & 18.18 \\
\hline $\mathrm{C}$ & $\begin{array}{l}\text { Resistant to all tested antibiotics except nitrofurantoin and } \\
\text { trimethoprim/sulfamethoxazole }\end{array}$ & 2 & 3.64 \\
\hline $\mathrm{D}$ & $\begin{array}{l}\text { Resistant to all tested antibiotics except trimethoprim/ } \\
\text { sulfamethoxazole }\end{array}$ & 6 & 10.91 \\
\hline $\mathrm{E}$ & $\begin{array}{l}\text { Resistant to all tested antibiotics except levofloxacin, ciprofloxacin, } \\
\text { nitrofurantoin, and trimethoprim/sulfamethoxazole }\end{array}$ & 2 & 3.64 \\
\hline $\mathrm{F}$ & Resistant to all tested antibiotics except tobramycin & 1 & 1.82 \\
\hline G & $\begin{array}{l}\text { Resistant to all tested antibiotics except levofloxacin and } \\
\text { nitrofurantoin }\end{array}$ & 4 & 7.27 \\
\hline $\mathrm{H}$ & $\begin{array}{l}\text { Resistant to all tested antibiotics except levofloxacin and } \\
\text { ciprofloxacin }\end{array}$ & 5 & 9.1 \\
\hline I & $\begin{array}{l}\text { Resistant to all tested antibiotics except levofloxacin, ciprofloxacin, } \\
\text { and trimethoprim/sulfamethoxazole }\end{array}$ & 26 & 47.27 \\
\hline
\end{tabular}

\section{Molecular detection of bla $_{N D M-1}$}

The sequencing of $b l a_{\mathrm{NDM}-1}$ amplicons (983 bp) was carried out and aligning of the $b l a_{\mathrm{NDM}-1}$ amplicon sequences with the reference strains in GenBank confirmed the correct identification of $b l a_{\mathrm{NDM}-1}$ gene among carbapenem-resistant 

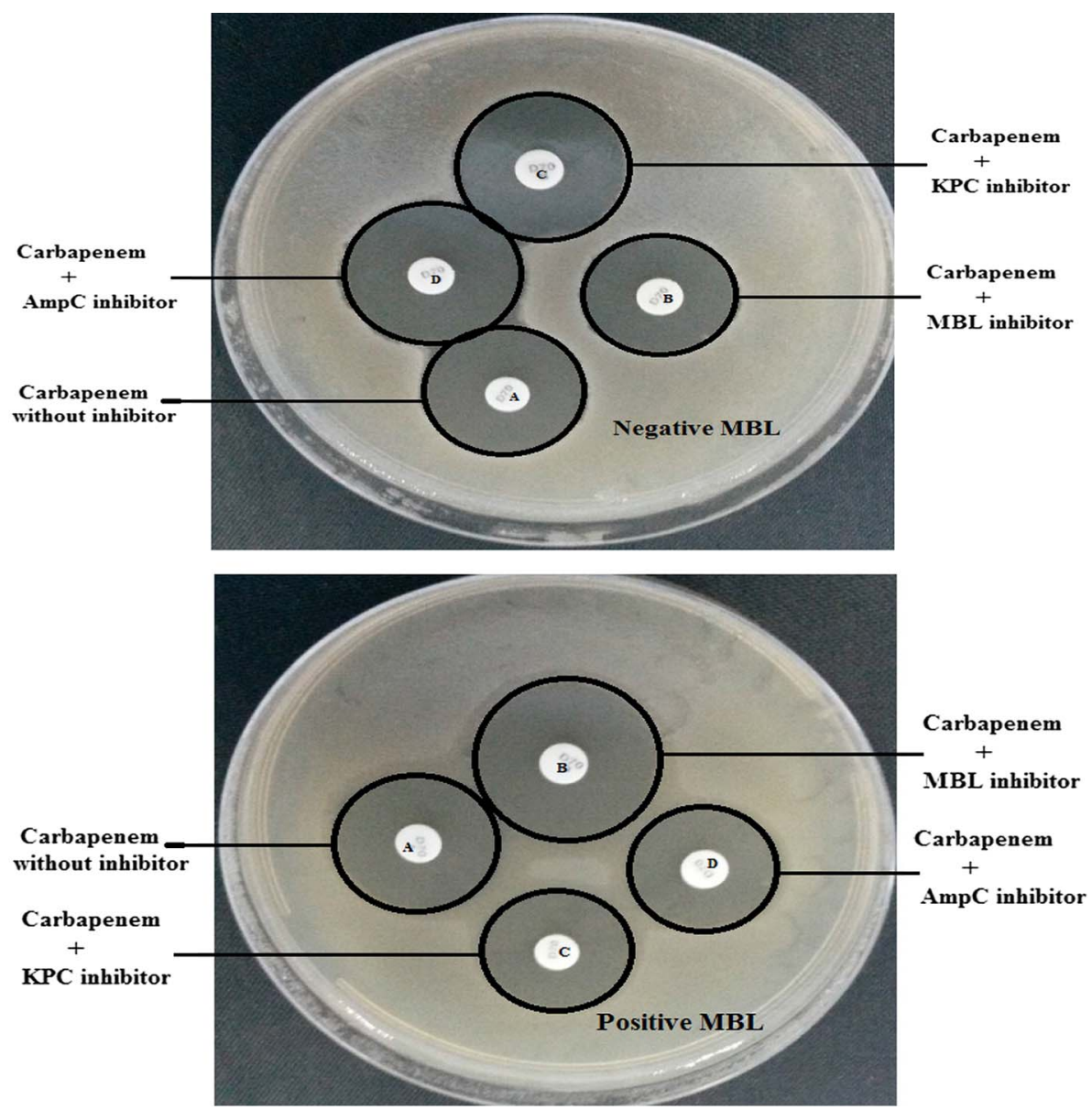

Figure 1. Phenotypic detection of metallo- $\beta$-lactamase production by MASTDISCS D70C (positive and negative $\mathrm{MBL}$ )

K. pneumoniae. The results showed the presence of a $b l a_{\mathrm{NDM}-1}$ gene (661 and 983 bp) in 37 (67.27\%) carbapenem-resistant K. pneumoniae strains. On the other hand, $18(32.73 \%)$ strains of carbapenem-resistant $K$. pneumoniae did not harbor $b a_{\mathrm{NDM}-1}$ gene as shown in Table II and Figures 2 and 3. The result showed the highest percentage of strains harboring $b l a_{\mathrm{NDM}-1}$ gene isolated from sputum specimens followed by strains isolated from burned wounds and the lowest percentage was from strains isolated from blood as shown in Table II. Out of 18 carbapenemresistant $K$. pneumoniae strains isolated from sputum, 14 (77.77\%) were harboring $b l a_{\mathrm{NDM}-1}$ gene and out of 14 strains isolated from burned wounds $10(71.43 \%)$ were 


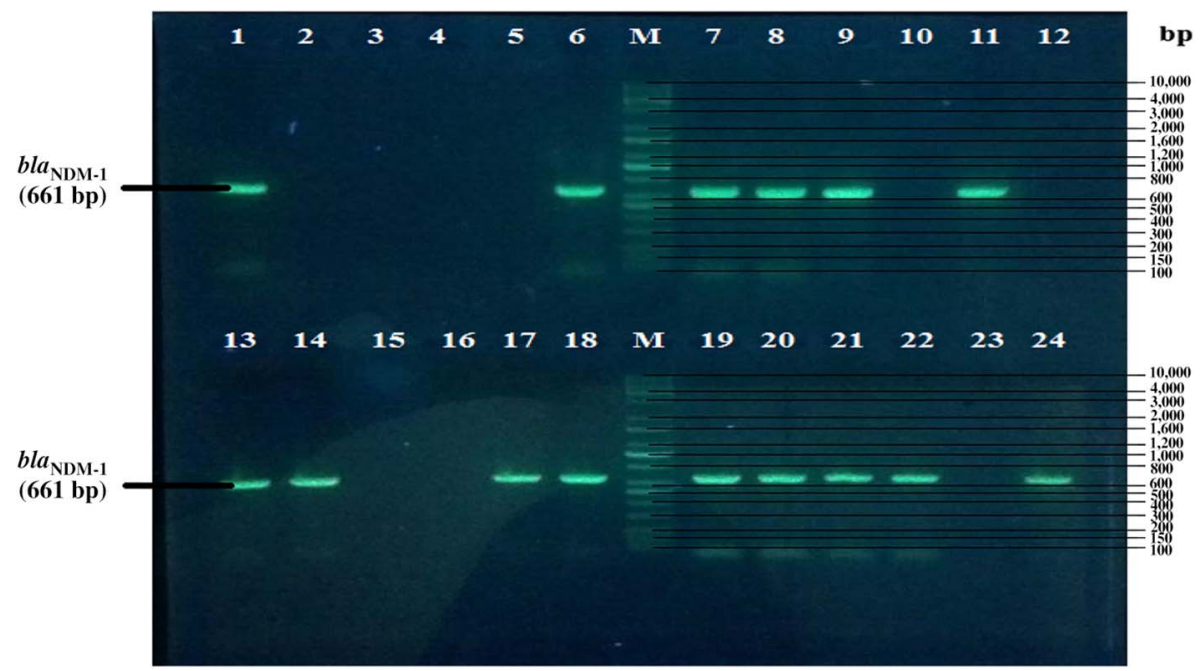

Figure 2. PCR amplification fragments for the detection of bla $a_{\mathrm{NDM}-1}$ gene (661 bp) among carbapenem-resistant Klebsiella pneumoniae ssp. pneumoniae strains. Lanes 1-24: Klebsiella pneumoniae ssp. pneumoniae strains; Lane M: 100-bp DNA ladder; Lane C: negative control. Amplicons were electrophoresed on agarose gel $(1 \%)$ at $5 \mathrm{~V} / \mathrm{cm}$ for $1 \mathrm{~h}$, stained with RedSafe

(iNtRON, Korea), and visualized using an UV transilluminator documentation system

harboring $b l a_{\mathrm{NDM}-1}$ gene, whereas out of 23 strains isolated from blood $13(56.52 \%)$ were harboring $b l a_{\mathrm{NDM}-1}$ gene (Table II).

Detection of $\mathrm{bla}_{I M P}, \mathrm{bla}_{V I M}$, bla $\mathrm{a}_{S I M}$, bla $\mathrm{a}_{G I M}$, and $\mathrm{bla}_{S P M}$ genes

The results of $b l a_{\mathrm{IMP}}, b l a_{\mathrm{VIM}}, b l a_{\mathrm{SIM}}, b l a_{\mathrm{GIM}}$, and $b l a_{\mathrm{SPM}}$ genes distribution of among carbapenem-resistant $K$. pneumoniae strains showed that only five strains were positive for $b l a_{\mathrm{IMP}}$ gene $5(9.1 \%)$, and none of the strains harbored bla $a_{\mathrm{VIM}}, b l a_{\mathrm{SIM}}, b l a_{\mathrm{GIM}}$, and bla $a_{\mathrm{SPM}}$ genes (Figures 3 and 4, Table II).

Real-time PCR for expression and detection of $\mathrm{bla}_{N D M-1}$ gene

Real-time PCR experiments for the $b l a_{\mathrm{NDM}-1}$ gene were performed among 55 carbapenem-resistant $K$. pneumoniae showed different expressions in different strains (Figure 5).

Phylogenetic tree

Phylogenetic tree based on the nucleotide sequences of the $b l a_{\mathrm{NDM}-1}$ gene was shown in Figure 6. The data for the phylogenetic analysis were obtained from 


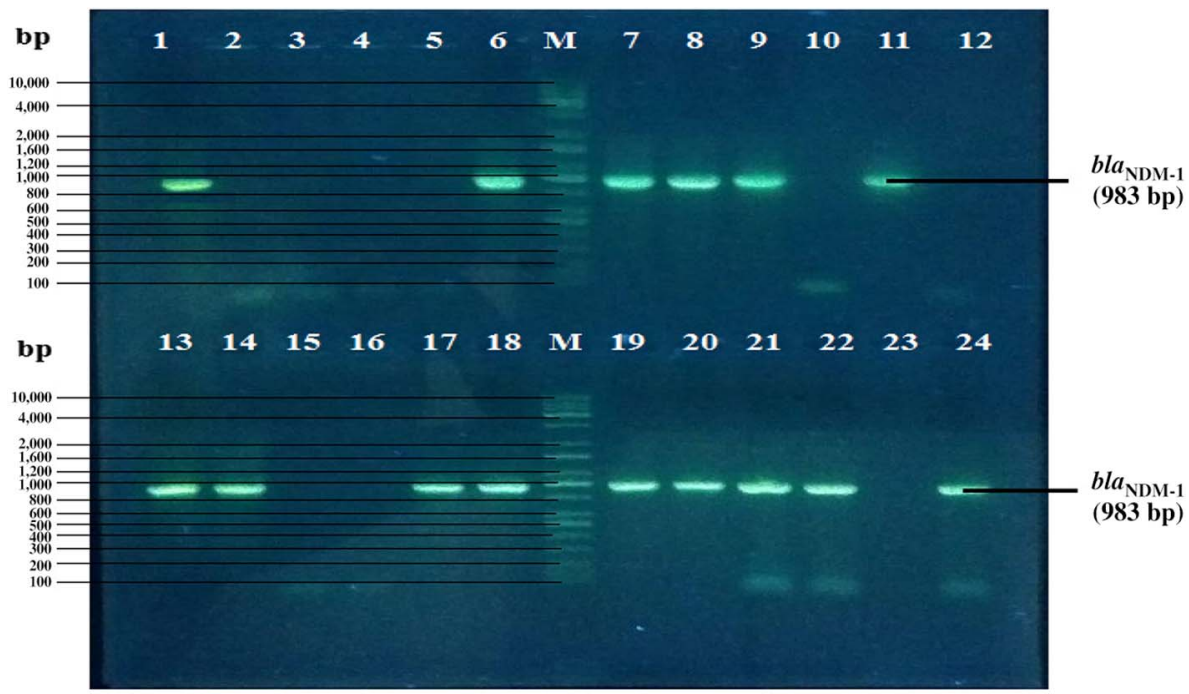

Figure 3. PCR amplification of the bla $a_{\mathrm{NDM}-1}$ gene (983 bp) in carbapenem-resistant Klebsiella pneumoniae ssp. pneumoniae strains. Lane M: 100-bp DNA ladder; Lanes 1-24: Klebsiella pneumoniae ssp. pneumoniae strains; Lane C: negative control. Amplicons were electrophoresed on agarose gel $(1 \%)$ at $5 \mathrm{~V} / \mathrm{cm}$ for $1 \mathrm{~h}$, stained with RedSafe (iNtRON, Korea), and visualized using an UV transilluminator documentation system

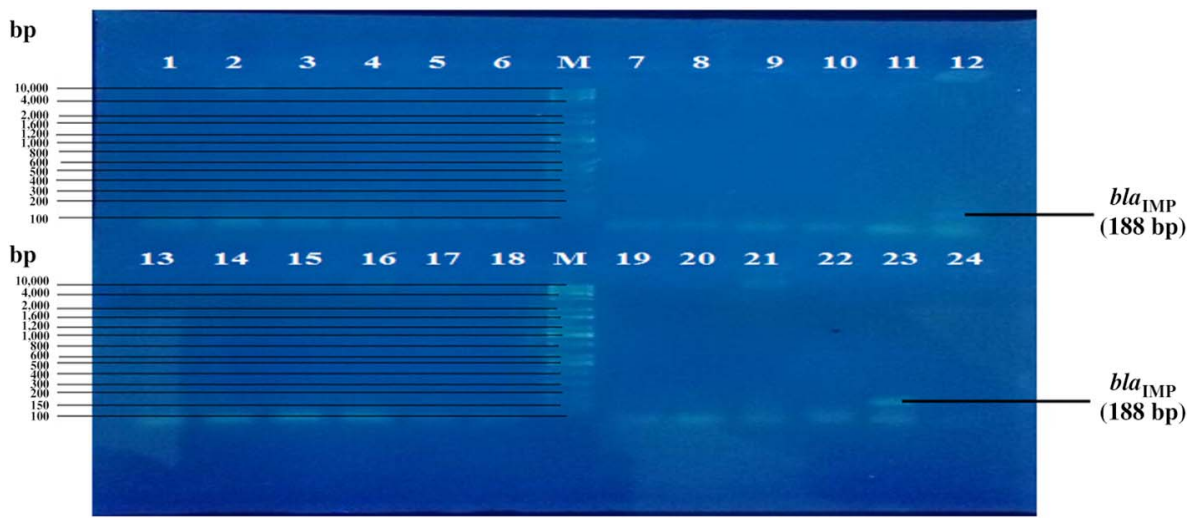

Figure 4. Multiplex PCR amplification of other MBL genes in carbapenem-resistant Klebsiella pneumoniae ssp. pneumoniae strains. Lane M: 100-bp DNA ladder; Lanes 1-55: Klebsiella pneumoniae ssp. pneumoniae strains; Lane C: negative control. Amplicons were electrophoresed on agarose gel (1\%) at $5 \mathrm{~V} / \mathrm{cm}$ for $1 \mathrm{~h}$, stained with RedSafe (iNtRON, Korea), and visualized using an UV transilluminator documentation system 


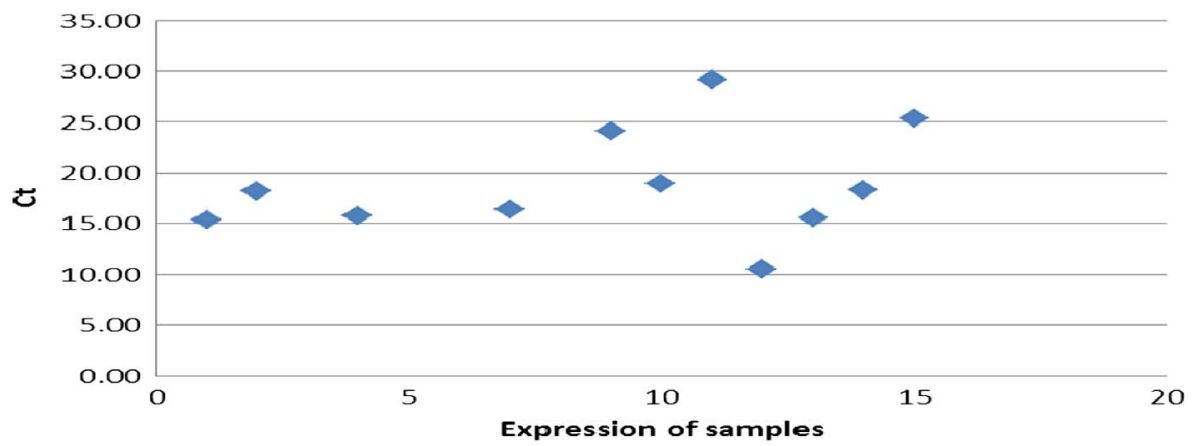

Figure 5. The expression of samples $\left(b l a_{\mathrm{NDM}-1}\right.$ gene)

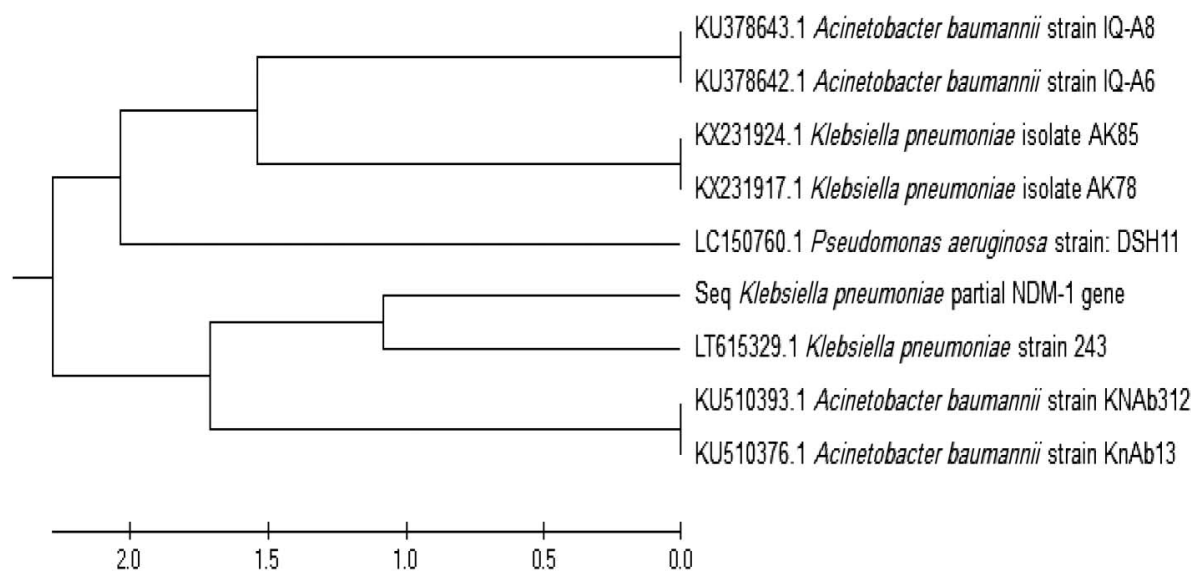

Figure 6. Phylogenetic tree based on the nucleotide sequences of the $b l a_{\mathrm{NDM}-1}$ gene

sequences in the GenBank nucleotide sequence database. Table II shows the accession numbers and the percentage of nucleotide identity and similarity of the bla $_{\mathrm{NDM}-1}$ gene for K. pneumoniae, Acinetobacter baumannii, and Pseudomonas aeruginosa sequences in the GenBank.

\section{Discussion}

Carbapenems are the drugs of choice against serious infections caused by Gram-negative bacteria, but several studies have reported the prevalence of MBL-producing clinical strains worldwide. Among MBL genes, NDM-1 has 
emerged and it confers resistance to all $\beta$-lactam antibiotics and being reported in $K$. pneumoniae, E. coli, and $A$. baumannii as the main hosts. NDM-1 gene from India and Pakistan has been specified as reservoirs of NDM producers [14, 15]. In Iraq, hardly any information regarding the NDM1 -producing $K$. pneumoniae is available. This study reports for the first time the presence of NDM-1 among $K$. pneumoniae in Baghdad, Iraq. Antibiotic susceptibility test results showed higher resistant rates for most of the antibiotics except levofloxacin. All the strains were multidrug-resistant showing nine different antimicrobial-resistant patterns and sensitive to levofloxacin $(85.45 \%)$.

The phenotypic detection of carbapenemases by MASTDISCS D70C revealed $29(52.73 \%)$ strains were MBL-producing, out of 55 were carbapenemresistant $K$. pneumoniae strains. This study evidenced the silent spread of NDM1-producing $(67.27 \%)$ K. pneumoniae strains from hospital settings in Baghdad, Iraq, which is significantly more than expected in any city of Iraq. Till date, more than six different $b l a_{\mathrm{NDM}-1}$ allotypes are known [16]. Since NDM-1 is carried on a plasmid or on chromosomes, the rapid emergence of $b l a_{\mathrm{NDM}-1}$ has been directly related to a transferable plasmid which has spread in many countries [16]. This is the first report on the prevalence of NDM-1 genes in Iraqi hospitals among $K$. pneumoniae isolates.

Several countries have reported the alarming spread of carbapenemresistant $E$. coli and $K$. pneumoniae, but NDM-1 has been reported only from Oman, a neighboring country [17]. Initially, NDM-1 was reported in $K$. pneumoniae and E. coli recovered from a Swedish patient transported from India [18]. Since then it has been disseminated widely in over 40 countries [19]. All these reports from different countries have indicated a probable source of NDM-1 producers from the Indian subcontinent, with both hospital and community acquisition and has spread to Austria, Australia, Belgium, Canada, Denmark, France, Germany, Kenya, the Netherlands, Norway, the Sultanate of Oman, and the United States [17, 20-22]. Following the initial identification of the $b l a_{\mathrm{NDM}-1}$ gene in clinical isolates from Egypt due to unknown sources, it can be concluded that the NDM-producing strains have already emerged and spread in the Middle East as in Iraq and Oman. Recently, a case of NDM-producing $K$. pneumoniae has been described in France from an Iraqi patient [23]. A study performed by Pesesky et al. [24] indicated the rapid spread of carbapenem resistance between strains. This study also underlines the spread of the $b l a_{\mathrm{NDM}-1}$ gene worldwide, as exemplified by the report of NDM-1-producing E. coli, Enterobacter cloacae, and $K$. pneumoniae in the United States [25], NDM-1-producing E. coli from Australia [26], and the dissemination of NDM-1 gene among K. pneumoniae 
isolates in Africa [27]. Bastian et al. [16] reported the first case of NDM-1-producing K. pneumoniae in Caribbean islands. Zheng et al. [28] reported plasmid encoding $b l a_{\mathrm{NDM}-1}$ from Enterobacteriaceae strains in several regions of China including Shanghai, Beijing, Shandong province, and Hong Kong.

A recent study from Turkey tested 77 isolates of $K$. pneumoniae and found that 74 isolates $(89.16 \%)$ produced OXA-48 carbapenemase, whereas nine isolates (10.84\%) produced both OXA-48 and NDM-1 by both phenotypic tests included CarbaNP test and CIM test [29]. Genotypic characterization of ESBL and carbapenemase genes by the Check-MDR CT102 was fully in agreement with phenotypic testing in the detection of $8 \mathrm{MBL}$ in study by Somily et al. [30].

Different genes are involved in carbapenem resistance among Enterobacteriaceae, which may vary from country to country. In this study, $b l a_{\mathrm{NDM}-1}$ and $b l a_{\text {IMP }}$ genes were detected by conventional PCR and the result showed 37 $(67.27 \%)$ strains harbored $b l a_{\mathrm{NDM}-1}$ gene, but only $5(9.1 \%)$ strains harbored $b l a_{\mathrm{IMP}}$ gene. Also, the results showed the coexistence of both $b l a_{\mathrm{NDM}-1}$ and $b l a_{\mathrm{IMP}}$ genes in three strains of $K$. pneumonia under the study. Our report is in contrary with other reports from Turkey, Greece, Saudi Arabia, and Israel where bla $a_{\text {VIM }}$ genes were reported rather than $b l a_{\mathrm{IMP}}$ genes [31-35]. On the other hand, no strain under the study carried $b l a_{\mathrm{VIM}}, b l a_{\mathrm{SIM}}, b l a_{\mathrm{GIM}}$, and $b l a_{\mathrm{SPM}}$ genes and thus we may conclude that $b l a_{\mathrm{NDM}-1}$ gene was responsible for the spread of resistance to carbapenems in these strains.

This study revealed that most carbapenem-resistant $K$. pneumoniae strains carried the bla $a_{\mathrm{NDM}-1}$ gene $37(67.27 \%)$ out of 55 strain and this is a high percentage compared with the countries of the world, which may attribute to the reason that many Iraqi patients transport for treatment in India and conduct various surgical procedures, thus leading to the gene transfer to Iraqi hospitals. Moreover, the treatment of patients infected with carbapenemresistant Enterobacteriaceae is more challenging due to their highlevel resistance as they very often carry on the same transposon the genes responsible for resistance to multiple antibiotics and also limited treatment options.

In conclusion, Iraq is also facing an alarming threat with the emergence of the imported NDM-1 gene in Enterobacteriaceae. Hence, it is necessary to follow proper infection control practices and physicians should be aware of the patients with such risk factors. A multidisciplinary approach to limit the spread of such organisms is essential followed by prevention, detection, proper antimicrobial stewardship, and adequate infection control measures should help in limiting the spread of these organisms. 


\section{Acknowledgements}

The authors would like to thank Al-Mustansiriyah University, Baghdad, Iraq (http://uomustansiriyah.edu.iq) for the support in this work.

\section{Conflict of Interest}

The author has nothing to disclose.

\section{References}

1. Zaman, T., Aldrees, M., Al Johani, S. M., Alrodayyan, M., Aldughashem, F. A., Balkhy, H. H.: Multi-drug carbapenem-resistant Klebsiella pneumoniae infection carrying the OXA-48 gene and showing variations in outer membrane protein 36 causing an outbreak in a tertiary care hospital in Riyadh, Saudi Arabia. Int J Infect Dis 28, 186-192 (2014).

2. Pitout, J. D., Nordmann, P., Poirel, L.: Carbapenemase-producing Klebsiella pneumoniae, a key pathogen set for global nosocomial dominance. Antimicrob Agents Chemother 59, 5873-5884 (2015).

3. Fazeli, H., Norouzi-Barough, M., Ahadi, A. M., Shokri, D., Solgi, H.: Detection of New Delhi metallo- $\beta$-lactamase-1 (NDM-1) in carbapenem resistant Klebsiella pneumoniae isolated from a university hospital in Iran. Hippokratia 19, 205-209 (2015).

4. Paterson, D. L.: Resistance in gram-negative bacteria: Enterobacteriaceae. Am J Infect Control 34, 20-28 (2006).

5. Nordmann, P., Poirel, L.: Strategies for identification of carbapenemase-producing Enterobacteriaceae. J Antimicrob Chemother 68, 487-489 (2013).

6. Nordmann, P., Poirel, L., Dortet, L.: Rapid detection of carbapenemase-producing Enterobacteriaceae. Emerg Infect Dis 18, 1503-1507 (2012).

7. Oteo, J., Hernandez, J. M., Espasa, M., Fleites, A., Saez, D., Bautista, V., Pérez-Vazquez, M., Fernández-García, M. D., Delgado-Iribarren, A., Sánchez-Romero, I., García-Picazo, L., Miguel, M. D., Solís, S., Aznar, E., Trujillo, G., Mediavilla, C., Fontanals, D., Rojo, S., Vindel, A., Campos, J.: Emergence of OXA-48-producing Klebsiella pneumoniae and the novel carbapenemases OXA-244 and OXA-245 in Spain. J Antimicrob Chemother 68, 317-321 (2012).

8. Singh, M., Kakati, B., Agarwal, R. K., Kotwal, A.: Detection of Klebsiella pneumoniae carbapenemases (KPCs) among ESBL/MBL producing clinical isolates of Klebsiella pneumoniae. Int J Curr Microbiol App Sci 4, 726-731 (2015).

9. Nordmann, P., Poirel, L., Carrer, A., Toleman, M. A., Walsh, T. R.: How to detect NDM-1 producers. J Clin Microbiol 49, 718-721 (2011).

10. Mulvey, M. R., Grant, J. M., Plewes, K., Roscoe, D., Boyd, D. A.: New Delhi metallo$\beta$-lactamase in Klebsiella pneumoniae and Escherichia coli, Canada. Emerg Infect Dis 17, 103-106 (2011). 
11. Bonnin, R. A., Naas, T., Poirel, L., Nordmann, P.: Phenotypic, biochemical, and molecular techniques for detection of metallo- $\beta$-lactamase NDM in Acinetobacter baumannii. J Clin Microbiol 50, 1419-1421 (2012).

12. Ellington, M. J., Kistler, J., Livermore, D. M., Woodford, N.: Multiplex PCR for rapid detection of genes encoding acquired metallo- $\beta$-lactamases. J Antimicrob Chemother 59, 321-322 (2007).

13. Sambrook, J., Fritsch, E. F., Maniatis, T.: Molecular Cloning: A Laboratory Manual, $2^{\text {nd }}$ Edition. Cold Spring Harbor Laboratory Press, Cold Spring Harbor, 1989, p. 68.

14. AL-Harmoosh, R. A., Jarallah, E. M.: First detection of the $b l a_{\mathrm{NDM}-1}$ and $b l a_{\mathrm{NDM}-2}$ genes in a clinical isolates of Acinetobacter baumannii in Hillah hospitals Iraq. Int J Adv Res $\mathbf{3}$, 1407-1416 (2015).

15. Nordmann, P., Poirel, L., Walsh, T. R., Livermore, D. M.: The emerging NDM carbapenemases. Trends Microbiol 19, 588-595 (2011).

16. Bastian, S., Nordmann, P., Creton, E., Malpote, E., Thiery, G., Martino, F., Breurec, S., Dortet, L.: First case of NDM-1 producing Klebsiella pneumoniae in Caribbean islands. Int J Infect Dis 34, 53-54 (2015).

17. Poirel, L., Al Maskari, Z., Al Rashdi, F., Bernabeu, S., Nordmann, P.: NDM-1-producing Klebsiella pneumoniae isolated in the Sultanate of Oman. J Antimicrob Chemother 66, 304-306 (2011).

18. Yong, D., Toleman, M. A., Giske, C. G., Cho, H. S., Sundman, K., Lee, K., Walsh, T. R.: Characterization of a new metallo- $\beta$-lactamase-1 gene, $b l a_{\mathrm{NDM}-1}$, and a novel erythromycin esterase gene carried on a unique genetic structure in Klebsiella pneumoniae sequence type 14 from India. Antimicrob Agents Chemother 53, 5046-5054 (2009).

19. Johnson, A. P., Woodford, N.: Global spread of antibiotic resistance: The example of New Delhi metallo- $\beta$-lactamase (NDM)-mediated carbapenem resistance. J Med Microbiol 62, 499-513 (2013).

20. Nordmann, P., Poirel, L., Toleman, M. A., Walsh, T. R.: Does broad spectrum beta-lactam resistance due to NDM-1 herald the end of the antibiotic era for treatment of infections caused by Gram-negative bacteria? J Antimicrob Chemother 66, 689-692 (2011).

21. Poirel, L., Hombrouck-Alet, C., Freneaux, C., Bernabeu, S., Nordmann, P.: Global spread of New Delhi metallo- $\beta$-lactamase 1. Lancet Infect Dis 10, 832 (2010).

22. Poirel, L., Ros, A., Carricajo, A., Berthelot, P., Pozzetto, B.: Extremely drug-resistant Citrobacter freundii isolate producing NDM-1 and other carbapenemases identified in a patient returning from India. Antimicrob Agents Chemother 55, 447-448 (2011).

23. Poirel, L., Fortineau, N., Nordmann, P.: International transfer of NDM-1-producing Klebsiella pneumoniae from Iraq to France. Antimicrob Agents Chemother 55, 18211822 (2011).

24. Pesesky, M. W., Hussain, T., Wallace, M., Wang, B., Andleeb, S., Burnham, C. D., Dantas, G.: KPC and NDM-1 genes in related Enterobacteriaceae strains and plasmids from Pakistan and the United States. Emerg Infect Dis 21, 1034-1037 (2015).

25. Centers for Disease Control and Prevention: Detection of Enterobacteriaceae isolates carrying metallo- $\beta$-lactamase, United States. MMWR Morb Mortal Wkly Rep 59, 750 (2010).

26. Poirel, L., Lagrutta, E., Taylor, P., Pham, J., Nordmann, P.: Emergence of metallo$\beta$-lactamase NDM-1-producing multidrug-resistant Escherichia coli in Australia. Antimicrob Agents Chemother 54, 4914-4916 (2010). 
27. Poirel, L., Revathi, G., Bernabeu, S., Nordmann, P.: Detection of NDM-1-producing Klebsiella pneumoniae in Kenya. Antimicrob Agents Chemother 55, 934-936 (2011).

28. Zheng, R., Zhang, Q., Guo, Y., Feng, Y., Liu, L., Zhang, A., Zhao, Y., Yang, X., Xia, X.: Outbreak of plasmid-mediated NDM-1-producing Klebsiella pneumoniae ST105 among neonatal patients in Yunnan, China. Ann Clin Microbiol Antimicrob 15, 1-8 (2016).

29. Yıldız, S. S., Kaşkatepe, B., Avcıküçük, H., Öztürk, Ş.: Performance of CarbaNP and CIM tests in OXA-48 carbapenemase-producing Enterobacteriaceae. Acta Microbiol Immunol Hung 64, 9-16 (2017).

30. Somily, A. M., Garaween, G. A., Abukhalid, N., Absar, M. M., Senok, A. C.: Comparison of molecular and phenotypic methods for the detection and characterization of carbapenem resistant Enterobacteriaceae. Acta Microbiol Immunol Hung 63, 69-81 (2016).

31. Ikonomidis, A., Labrou, M., Afkou, Z., Maniatis, A. N., Sofianou, D., Tsakris, A., Pournaras, S.: First occurrence of an Escherichia coli clinical isolate producing the VIM-1/VIM-2 hybrid metallo- $\beta$-lactamase VIM-12. Antimicrob Agents Chemother 51, 3038-3039 (2007).

32. Giakkoupi, P., Pappa, O., Polemis, M., Vatopoulos, A. C., Miriagou, V., Zioga, A., Papagiannitsis, C. C., Tzouvelekis, L. S.: Emerging Klebsiella pneumoniae isolates coproducing KPC-2 and VIM-1 Carbapenemases. Antimicrob Agents Chemother 53, 4048-4050 (2009).

33. Pournaras, S., Poulou, A., Voulgari, E., Vrioni, G., Kristo, I., Tsakris, A.: Detection of the new metallo- $\beta$-lactamase VIM-19 along with KPC-2, CMY-2 and CTX-M-15 in Klebsiella pneumonia. J Antimicrob Chemother 65, 1604-1607 (2010).

34. Leavitt, A., Navon-Venezia, S., Chmelnitsky, I., Schwaber, M. J., Carmeli, Y.: Emergence of KPC-2 and KPC-3 in carbapenem-resistant Klebsiella pneumoniae strains in an Israeli hospital. Antimicrob Agents Chemother 51, 3026-3029 (2007).

35. Gacar, G. G., Midilli, K., Kolayli, F., Ergen, K., Gundes, S., Hosoglu, S., Karadenizli, A., Vahaboglu, H.: Genetic and enzymatic properties of metallo- $\beta$-lactamase VIM-5 from a clinical isolate of Enterobacter cloacae. Antimicrob Agents Chemother 49, 4400-4403 (2005). 